
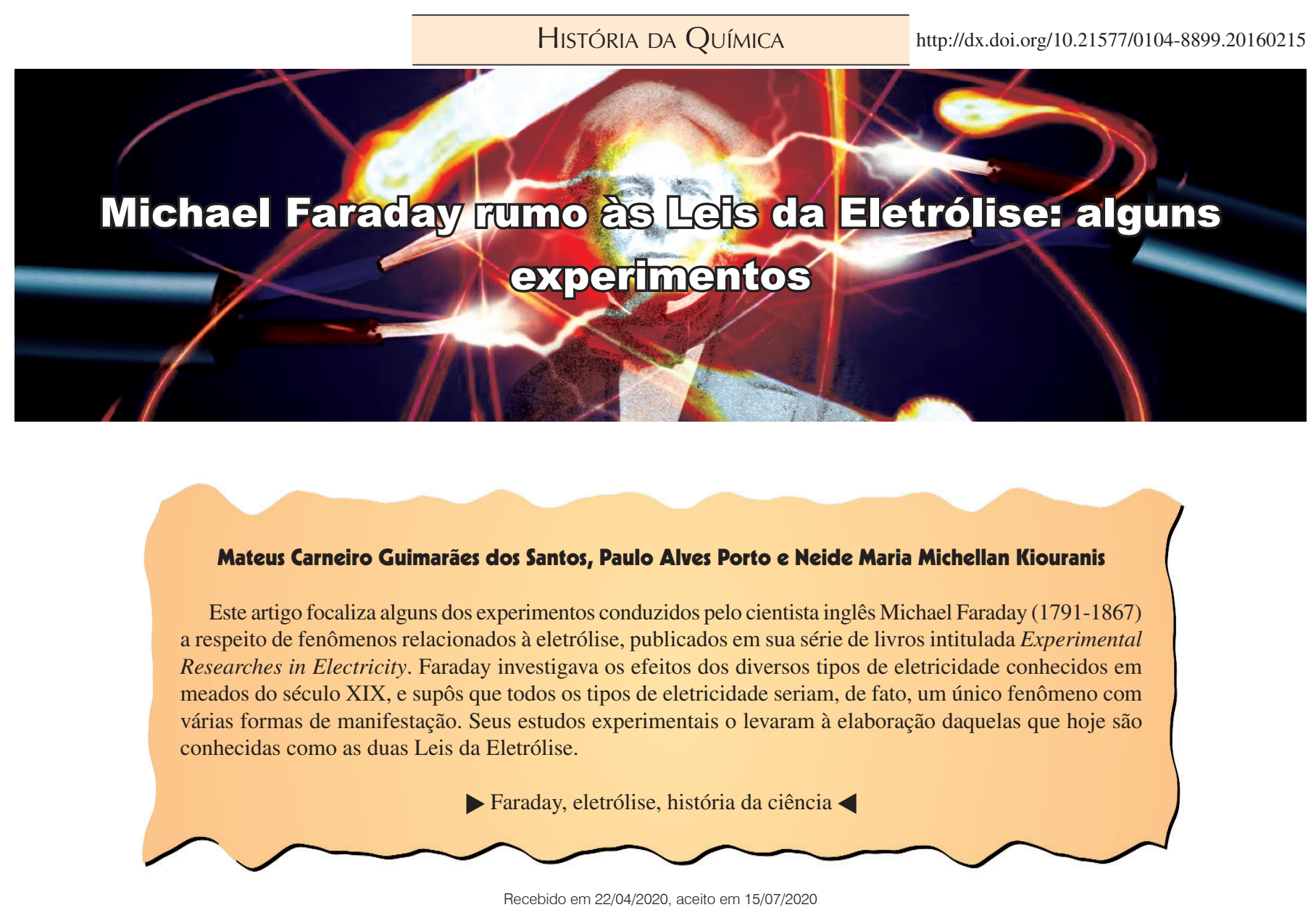

$\mathbf{A}$ importância de Michael Faraday para a história da ciência é realmente notável. O cientista inglês realizou uma série de contribuições para o desenvolvimento da ciência, tais como a indução eletromagnética, o isolamento de diversos compostos como o benzeno e buteno, a liquefação de gases como cloro, dióxido de nitrogênio, dióxido de enxofre e iodeto de hidrogênio, entre muitos outros trabalhos (Thomas, 1991). Faraday também elaborou, em colaboração com William Whewell (1794-1866), a nomenclatura que ainda é utilizada na eletroquímica, incluindo termos como eletrodo, ânodo, cátodo, íon, ânion, cátion, eletrólito e eletrólise (Ross, 1961; Ihde, 1984) - sendo que alguns deles adquiriram novos significados com o passar do tempo.

O nome de Faraday está associado, no ensino de química, às chamadas Leis da Eletrólise. $\mathrm{O}$ estudo do processo que levou Faraday à elaboração dessas leis, abordado neste artigo, pode ser útil, em contextos didáticos, para o entendimento de alguns conceitos fundamentais de eletroquímica, e também para que estudantes possam compreender como a ciência se desenvolveu e ainda se desenvolve.

Michael Faraday nasceu em 22 de setembro do ano de 1791, em uma localidade ao sul de Londres chamada

Esta seção contempla a história da Química como parte da história da ciência, buscando ressaltar como o conhecimento científico é construído.
Newington Butts, às margens do rio Tâmisa. Era o terceiro filho do ferreiro James Faraday e de sua mulher Margaret Hastwell, uma família de origem humilde, sem muitos recursos para educação ou mesmo para a alimentação de seus filhos. Logo se mudaram para Londres, onde as possibilidades de emprego eram maiores para o ofício de seu pai (Baldinato, 2009).

$\mathrm{O}$ início da educação do futuro cientista ocorreu em uma escola comum, onde Faraday pode aprender um pouco sobre leitura, escrita e aritmética (Bence-Jones, 1870, p. 9; Baldinato, 2009). Já em Londres, aos 13 anos Faraday conseguiu um emprego para ajudar nas despesas da família, como garoto de entregas de George Riebau, um vendedor de livros. A promessa era de que, após um ano de teste, ele poderia se tornar aprendiz de encadernador. Ao final desse período, o jovem Faraday foi aprovado, com a perspectiva de se tornar encadernador e procurar um emprego próprio após sete anos. Como aprendiz, Faraday tinha muito tempo para ler os livros em cuja encadernação estava trabalhando. Desde o início, mostrou-se interessado por livros de caráter científico (James, 1991).

Ao fim dos sete anos como aprendiz de encadernador, Faraday passou a buscar um trabalho que tivesse ligação com a ciência. Enviou cartas para Sir Joseph Banks, então presidente da Royal Institution, mas não obteve sucesso. Em 1813, Humphry Davy (1778-1829) - então o principal 
pesquisador e conferencista da Royal Institution - feriu os olhos em um experimento, e decidiu contratar um auxiliar. Assim, Faraday conseguiu um emprego naquela instituição, que lhe abriu os caminhos para sua bem sucedida carreira científica (Thompson, 1898).

Faraday se interessava por diversos campos das Ciências Naturais, e era um autodidata. Alguns de seus trabalhos mais famosos e reconhecidos se encontram em uma série de livros intitulados Experimental Researches in Electricity (Faraday, 1839). No presente artigo, nosso objetivo é apresentar alguns dos experimentos relacionados à eletrólise descritos por Faraday nessa série. Nosso foco recai sobre uma sequência de experimentos na qual Faraday, que inicialmente procurava demonstrar a identidade das diferentes manifestações dos fenômenos elétricos, seguiu por um caminho que o levou a expressar o que hoje chamamos de Leis da Eletrólise.

\section{Experimental Researches in Electricity}

Faraday iniciou suas investigações sobre eletricidade revisando e repetindo o que acreditava serem todos os experimentos que envolviam eletromagnetismo conhecidos na época, e publicou seus resultados no periódico Annals of Philosophy. A partir daí, Faraday começou a realizar novos experimentos, seguindo suas próprias ideias. Entre 1831 e 1852, o cientista britânico publicou uma série de monografias nos periódicos Philosophical Transactions of the Royal Society, Proceedings of the Royal Institution e Philosophical Magazine, que foram posteriormente reunidas em forma de livros, em três volumes intitulados Experimental Researches in Electricity (Faraday, 1839).

A leitura do sumário de Experimental Researches in Electricity já revela a grande variedade de conteúdos referentes à eletricidade investigados por Faraday. Neste artigo, focalizamos a terceira seção do volume 1, uma comunicação feita à Royal Society originalmente em 10 e 17 de janeiro de 1833, que se constitui no passo inicial para que Faraday chegasse posteriormente às Leis da Eletrólise.

A terceira seção se inicia com um tema bastante controverso para a época. Desde o século XVII até meados do
XIX, os estudiosos europeus que investigavam os fenômenos elétricos descreviam a existência de vários tipos de eletricidade, como se pode ver no Quadro 1.

Faraday suspeitava que não existiam vários tipos de eletricidade, mas várias fontes, todas produzindo um mesmo fenômeno. Para tentar provar que todos os tipos de eletricidade conhecidos eram a mesma coisa, Faraday propôs uma série de experimentos. Segundo ele,

Os efeitos da eletricidade em movimento ou correntes elétricas podem ser considerados como: $1^{\circ}$. evolução de calor; $2^{\circ}$. magnetismo; $3^{\circ}$. decomposição química; $4^{o}$. fenômenos fisiológicos; $5^{\circ}$. faísca. Será meu objetivo comparar as eletricidades de diferentes fontes, e especialmente as eletricidades comum e voltaica, pelo poder de produzir esses efeitos (Faraday, 1839, p. 78, §267, tradução nossa).

Como visto na citação acima, alguns critérios foram elaborados para os ensaios experimentais, norteados pelos efeitos causados pelos diversos tipos de eletricidade conhecidos até aquele momento. Nessa seção do livro, Faraday analisou cada tipo de eletricidade com relação a esses critérios. Os resultados podem ser vistos no Quadro 2, que reproduz uma tabela que consta do primeiro volume de Experimental Researches in Electricity (Faraday, 1839, p. 102).

Faraday concluiu, com base nos resultados apresentados na tabela, que a eletricidade era idêntica independente da fonte. Esse estudo foi bastante importante, pois deu início a reflexões mais profundas de Faraday sobre a eletricidade proveniente das fontes comum (originada por máquinas eletrostáticas) e voltaica (originada por pilhas voltaicas) - não apenas para confirmar a questão da identidade, mas também para elucidar alguns princípios básicos. Esses estudos deram origem ao que hoje chamamos de Leis da Eletrólise, conforme veremos na sequência.

\section{Os experimentos de eletrodecomposição}

Um dos experimentos feitos por Faraday para tentar mostrar que as duas eletricidades eram, de fato, a mesma,

Quadro 1:Os diversos tipos de eletricidade conhecidos entre os séculos XVII e XIX

\begin{tabular}{|c|c|c|c|}
\hline Ano & Eletricidade & Origem e Descrição & Pesquisador \\
\hline 1660 & Comum & Máquina eletrostática, atmosfera (relâmpagos). & Otto Von Guericke \\
\hline 1790 & Animal & Proveniente de músculos de animais. & Luigi Galvani \\
\hline 1800 & Voltaica & Gerada pela pilha de Volta. & Alessandro Volta \\
\hline 1821 & Térmica & Conversão de diferença de temperatura em eletricidade. & Thomas J. Seebeck \\
\hline 1831 & Magnética & Proveniente de uma máquina de ímãs. & Michael Faraday \\
\hline
\end{tabular}

Fonte: Os autores 


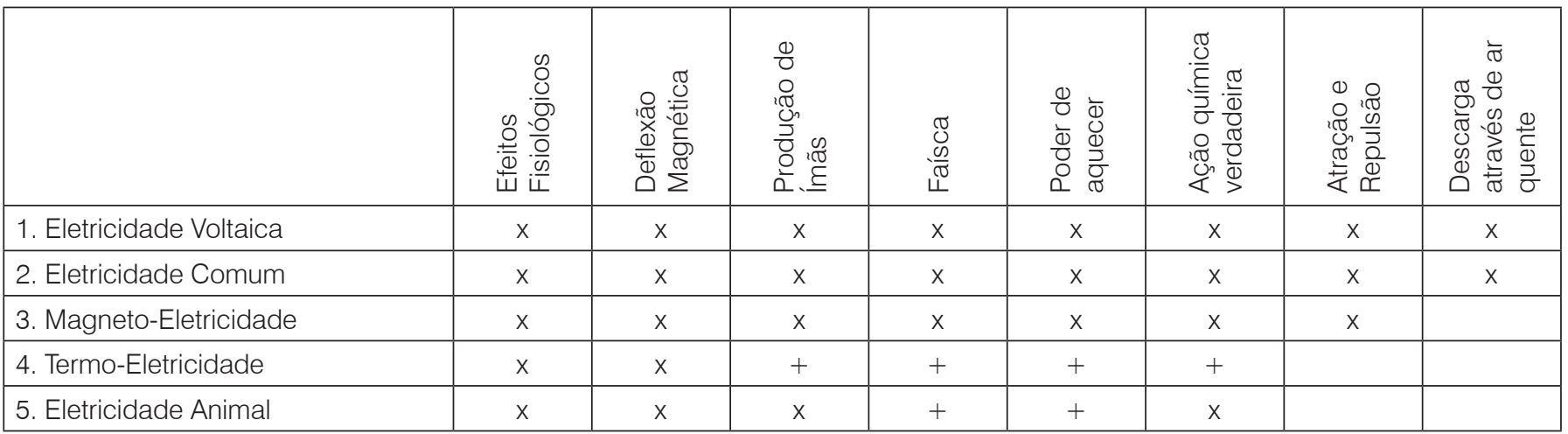

Fonte: Faraday, 1839, p.102. ${ }^{1}$

foi descrito na terceira seção do livro (Faraday, 1839, p. 90, §321) e discutido em detalhes na quinta seção ${ }^{2}$. Esse experimento tinha como objetivo investigar se a eletricidade comum poderia realizar a eletrodecomposição, promovendo uma reação química que originaria ácido e base.

Faraday preparou três tiras de papel, cada uma delas contendo em uma ponta tornassol (usado como indicador da presença de ácido, e identificado na Figura 1 com a letra $p$ ) e na outra ponta cúrcuma (indicador da presença de base, correspondendo à letra $n$ na Figura 1). Essas tiras foram umedecidas com uma solução de sulfato de sódio e apoiadas sobre uma placa de vidro. Conforme ilustrado na Figura 1, Faraday ligou um fio de platina $m$ a uma máquina eletrostática, sendo que o terminal $t$ servia para a descarga da corrente ${ }^{3}$. No esquema, $r$ e $s$ representam fios de platina utilizados para a condução elétrica entre os papéis indicadores previamente umedecidos no eletrólito.

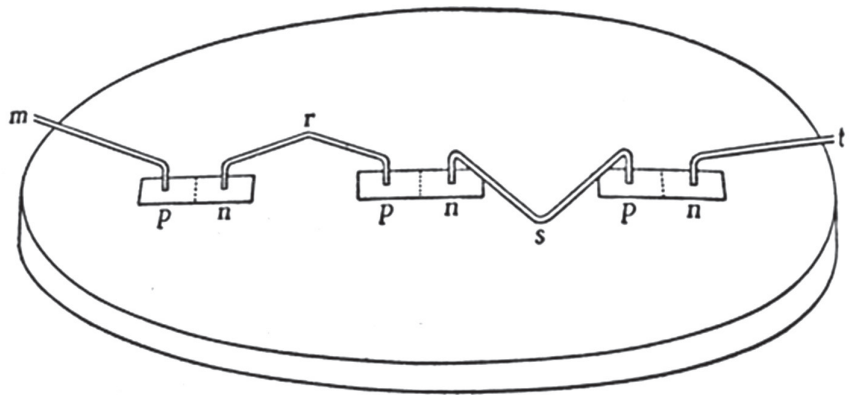

Figura 1: Ilustração do experimento de Faraday para eletrodecomposição da solução de sulfato de sódio. Fonte: Faraday (1839, Prancha III, figura 45)

Colocando em operação a máquina eletrostática, em pouco tempo os indicadores mostravam a presença de ácido nos pedaços de papel de tornassol e de base nos pedaços de papel de cúrcuma, permitindo concluir que a eletricidade gerada pela máquina eletrostática era capaz de realizar a eletrodecomposição, da mesma forma que a eletricidade gerada por uma pilha voltaica (Faraday, 1839, p. 89, §319; Drennan, 1965).

Nessa investigação, Faraday realizou experimentos envolvendo a eletrodecomposição de diversas substâncias, entre elas o iodeto de potássio. Em relação a essa substância, era possível fazer o acompanhamento visual de sua decomposição em solução aquosa embebida em um papel branco, devido à formação de uma mancha escura ${ }^{4}$. Faraday preparou uma folha de papel de filtro dobrada em quatro e embebida em uma solução de iodeto de potássio, apoiada sobre uma espátula de platina. Sobre o papel dobrado foi encostada a extremidade de um fio de platina. Em um primeiro arranjo, o fio de platina foi ligado à máquina eletrostática, e a espátula foi ligada ao dispositivo de aterramento. Faraday fazia girar o disco cuja fricção gerava a eletricidade, e observava o aparecimento da mancha colorida no papel junto ao fio de platina: a intensidade da cor era proporcional ao número de voltas do disco. Faraday observou que eram necessárias trinta voltas da máquina para produzir uma mancha de iodo tão intensa que penetrava na segunda dobra do papel. No segundo arranjo, o fio de platina foi ligado ao terminal positivo de uma pilha feita com eletrodos de platina e zinco em solução de ácido sulfúrico (em condições padronizadas por Faraday), enquanto a espátula foi ligada ao terminal negativo da pilha. Faraday então observou que o tempo necessário para a mancha de iodo alcançar a segunda dobra do papel correspondia a oito batidas de seu relógio ${ }^{5}$ (Faraday, 1839, pp. 106-107, §373-375; Drennan, 1965; Stock, 1991). Segundo ele,

Após alternar e repetir os experimentos comparativos muitas vezes, encontrou-se de maneira constante que esta corrente padrão de eletricidade voltaica, mantida durante oito batidas do relógio, era igual, em efeito químico, a trinta voltas da máquina [eletrostática]... (Faraday, 1839, p. 107, §375, tradução nossa.)

Faraday interpretou esses resultados como evidências de que os dois tipos de eletricidade (voltaica e comum) eram exatamente o mesmo fenômeno, pois tinham o mesmo efeito de eletrodecomposição. Em suas palavras:

Eu provei em uma recente série destas Researches (ao menos para minha satisfação) a identidade das 
eletricidades derivadas de diferentes fontes, e insisti especialmente nas provas da igualdade daquelas [eletricidades] obtidas pelo uso da máquina elétrica comum e da bateria voltaica (Faraday, 1839, p. 127, $\S 450$, tradução nossa).

Ao recorrer à eletrodecomposição para evidenciar a identidade dos tipos de eletricidade, Faraday indicava haver alguma relação entre a eletricidade e a "afinidade" que faz os elementos químicos ficarem juntos ou se separarem. Nessa mesma obra, Faraday indicou implicações desse experimento, sugerindo o caminho para a formulação posterior da primeira Lei da Eletrólise: “[...] para esse caso de decomposição eletroquímica, e provavelmente para todos os casos, a força química, assim como a força magnética, é diretamente proporcional à quantidade absoluta de eletricidade que passa" (Faraday, 1839, p. 107, §377, tradução nossa). Em um enunciado moderno, a primeira Lei da Eletrólise expressa que a massa da substância formada em um eletrodo é diretamente proporcional à quantidade de eletricidade que passa pelo sistema eletrolítico (Stock, 1991; Drennan, 1965). ${ }^{6}$

\section{Os equivalentes eletroquímicos}

Ao sugerir que a relação entre a "força química" e a quantidade de eletricidade "provavelmente" seria sempre observada, Faraday especulava sobre uma possível propriedade relacionada à estrutura da matéria. Nessa época, a hipótese atômica estava longe de ser consensualmente aceita pela comunidade científica, e Faraday tinha muitas dúvidas sobre ela. Segundo Faraday,

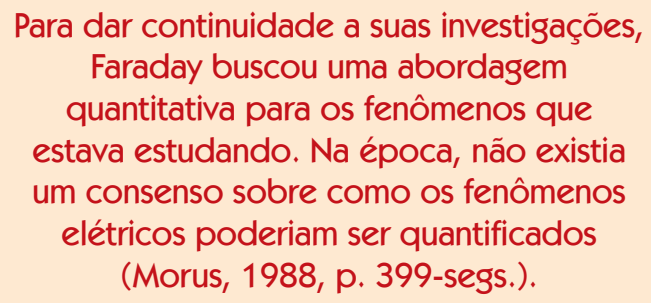

Figura 2: Volta-eletrômetro. Fonte: Faraday (1839, Prancha V, figura 64).

peças metálicas imersas em água acidulada, provocando sua decomposição em hidrogênio e oxigênio, que podiam ser coletados em um mesmo tubo ou em tubos separados. $\mathrm{O}$ volume total dos gases produzidos era medido, de modo que se estabelecia uma relação entre esse valor e a quantidade de eletricidade: quanto maior o volume de gases, maior a quantidade de eletricidade fornecida pelo dispositivo conectado ao volta-eletrômetro (Faraday, 1839, pp. 215-217, §732-741).

Dispondo desse instrumento de medida, Faraday se dispôs a investigar a hipótese de que o chamado peso equivalente de uma
Embora não saibamos nada sobre o que é um átomo, não podemos resistir em formar alguma ideia sobre partículas pequenas que representem o átomo para a mente [...] [E]xiste uma imensidão de fatos que nos justificam acreditar que os átomos de matéria são de alguma forma dotados de ou associados a forças elétricas... (Faraday, 1839, p. 249, §852, tradução nossa).

Para dar continuidade a suas investigações, Faraday buscou uma abordagem quantitativa para os fenômenos que estava estudando. Na época, não existia um consenso sobre como os fenômenos elétricos poderiam ser quantificados (Morus, 1988, p. 399-segs.). Faraday enfrentou esse problema construindo um instrumento denominado de volta-eletrômetro, ilustrado na Figura 2.

$\mathrm{O}$ princípio de funcionamento do volta-eletrômetro se baseava no fenômeno da eletrólise da água. A eletricidade produzida pelo dispositivo a ser testado era conduzida por substância produzida por eletrodecomposição seria o mesmo determinado por meio de transformações químicas comuns. Neste ponto, é relevante explicar o que se entendia por peso equivalente na época de Faraday. Também chamados de equivalentes químicos, os pesos equivalentes correspondiam às quantidades em massa das substâncias que podiam reagir completamente com (ou conter em sua composição) uma determinada massa de uma substância adotada como padrão. Ou seja, o peso equivalente era uma grandeza determinada empiricamente. Por exemplo, tomando como padrão 8 unidades de massa de gás oxigênio, o peso equivalente do gás hidrogênio seria 1 unidade, e o peso equivalente da água seria 9 unidades (pois a proporção em massa com que os gases oxigênio e hidrogênio se combinam é de 8 para 1 , resultando em 9 unidades de massa de água). O oxigênio foi escolhido na época como padrão por muitos autores, devido à facilidade em fazê-lo reagir com uma grande variedade de substâncias simples e compostas. Faraday decidiu então comparar o peso equivalente de uma substância, determinado 
pelos métodos químicos usuais, com o valor obtido por meio da eletrodecomposição.

A motivação de Faraday para o cálculo do equivalente químico por meio de um experimento de eletrólise foi dada pelas ideias de Davy e Jöns J. Berzelius (1779-1848), que acreditavam ser a afinidade química o resultado das atrações elétricas entre as partículas de matéria (Faraday, 1839, p. 206, §703).

Em meados do século XIX, havia muita controvérsia em torno da utilidade da hipótese atômica formulada por John Dalton (1766-1844), uma vez que a comunidade científica estava dividida entre atomistas e equivalentistas (Camel et al., 2009). Os atomistas seguiam a hipótese de Dalton sobre o átomo ser indivisível, indestrutível e maciço. Os equivalentistas, por sua vez, eram, em sua maioria, influenciados pelo positivismo de Augusto Comte (1798-1857), e preferiam basear suas teorias em fenômenos experimentais, ou seja, que pudessem ser observados empiricamente (Russel, 2017). O fato de que os equivalentistas não podiam obter evidências diretas da existência dos átomos os levavam a não trabalhar com essa hipótese. O próprio Faraday manifestava suas dúvidas em relação à hipótese atômica, e preferiu fazer referência aos pesos equivalentes de Berzelius (e não a pesos atômicos).

Mas devo confessar que tenho desconfiança do termo átomo; pois embora seja muito fácil falar de átomos, é muito difícil formar uma ideia clara da natureza deles, especialmente quando se considera corpos compostos (Faraday, 1839, p. 256, $\S 869$, tradução nossa).

Descrevemos a seguir um dos experimentos de determinação de peso equivalente conduzido por Faraday, e comunicado à Royal Society em 1834. Seu objetivo aqui era determinar o peso equivalente do estanho, por meio da decomposição de "protocloreto de estanho", atualmente conhecido como cloreto de estanho (II), ou cloreto estanoso (Faraday, 1839, p. 232, $\$ 789$-segs.). O aparato experimental incluía um fio de platina enrolado, que servia como cátodo, e que foi inicialmente pesado e inserido em um tubo de vidro. O cloreto estanoso foi introduzido no mesmo tubo (à esquerda na Figura 3) e aquecido até a fusão, sendo que outro fio de platina fazia a função de ânodo. O cátodo foi conectado a um volta-eletrômetro (esquematizado à direita na Figura 3 , que mostra apenas seus eletrodos e parte do tubo cilíndrico no qual se recolhem os gases formados), e o circuito foi fechado com uma bateria voltaica (não representada na Figura 3, mas com seus terminais positivo e negativo indicados, respectivamente, pelas letras $p$ e $n$ ). Ao final do experimento, Faraday observou a produção do cloreto de estanho (IV) (cloreto estânico) no ânodo, enquanto o estanho metálico produzido no cátodo formou uma liga com platina, líquida na temperatura do experimento. O final do experimento foi definido por Faraday como sendo após a coleta, no volta-eletrômetro, de um volume de gás igual a 3,85 polegadas cúbicas. Então, o ânodo foi removido da massa fundida. O tubo de vidro foi aberto e, após a remoção de sal e vidro, o cátodo foi pesado novamente, para que fosse determinado o peso de estanho metálico formado no experimento (Faraday, 1839, p. 232, §789-segs.).

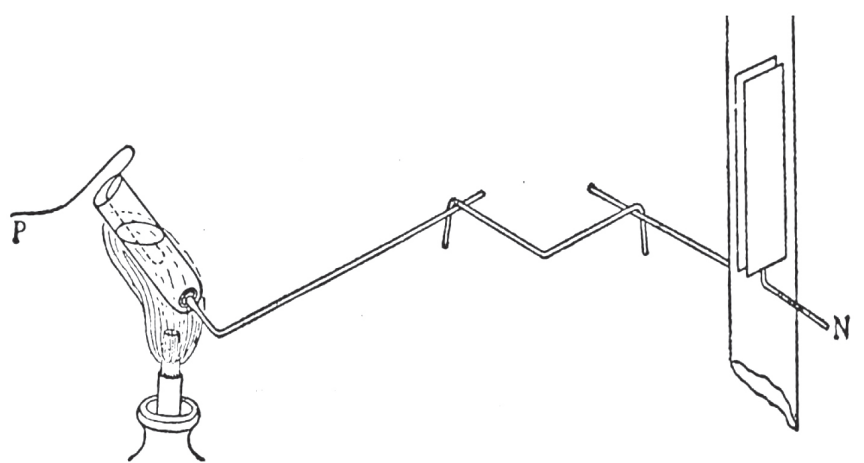

Figura 3: Esquema da aparelhagem para determinação do equivalente químico do estanho. Fonte: Faraday (1839, Prancha $\mathrm{V}$, figura 69). dos em um de seus experimentos: antes do procedimento, o cátodo pesava 20 grãos $^{7}$ e, após a deposição, pesava 23,2 grãos. Portanto, a massa de estanho metálico formada no eletrodo foi de 3,2 grãos. A quantidade de hidrogênio e oxigênio coletados no volta-eletrômetro foi de 3,85 polegadas cúbicas $\left(\mathrm{pol}^{3}\right)$. Faraday considerou, ainda, o dado empírico de que a decomposição de 12,92 grãos de água produzia 100 polegadas cúbicas de oxigênio e hidrogênio. Fazendo uma relação matemática simples, que pode ser vista a seguir, pode-se calcular a massa de água que produz $3,85 \mathrm{pol}^{3}$ de hidrogênio e oxigênio. Tal valor é igual a 0,49742 grãos de água. ${ }^{8}$

\section{$100 \mathrm{pol}^{3}$ de hidrogênio e oxigênio - 12,92 grãos de água \\ $3,85 \mathrm{pol}^{3}$ de hidrogênio e oxigênio - $m$ grãos de água $m=0,49742$ grãos de água}

Em seguida, Faraday tratou de calcular o equivalente químico do estanho, relacionando o valor obtido com o equivalente químico da água, determinado na época como sendo 9. Por meio de um cálculo simples, mostrado a seguir ${ }^{9}$, Faraday encontrou o valor de 57,9 para o peso equivalente do estanho, resultado igual ao valor determinado por Berzelius usando métodos químicos (Faraday, 1839, pp. 232-233, \$789-792).

$$
\begin{gathered}
\text { 0,49742 grãos de água - 3,20 grãos de } S n \\
9 \text { eq de água }-\mathrm{X} \text { eq de } \mathrm{Sn} \\
X=57,9 \mathrm{eq}
\end{gathered}
$$


Faraday reconheceu, entretanto, que o experimento foi repetido quatro vezes, e o valor médio das quatro determinações resultou em 58,53 para o peso equivalente do estanho (um pouco maior, portanto, que o valor obtido por Berzelius) (Faraday, 1839, p. 233, §792). Além do estanho, Faraday também realizou uma série de experimentos para o chumbo (usando diversos compostos desse metal, em diferentes condições) - obtendo resultados próximos ao valor disponível na literatura da época - e também para o antimônio e o bismuto - com os quais não obteve os resultados esperados, em função de uma variedade de dificuldades experimentais (Faraday, 1839, pp. 233-237, §794-806). No entanto, Faraday observou que havia sempre proporcionalidade entre a quantidade de eletricidade envolvida e as massas dos produtos formados em um experimento de eletrodecomposição, e que as massas desses produtos guardavam entre si a mesma proporção que suas massas equivalentes (o que viria a ser chamada de $2^{\mathrm{a}}$. Lei da Eletrólise). Na mesma seção de seu livro Experimental Researches in Electricity, o cientista britânico nomeou seus resultados como "Equivalentes eletroquímicos" e afirmou que "Equivalentes eletroquímicos coincidem e são os mesmos que os equivalentes químicos comuns" (Faraday, 1839, p. 245, §836, tradução nossa).

\section{Considerações finais}

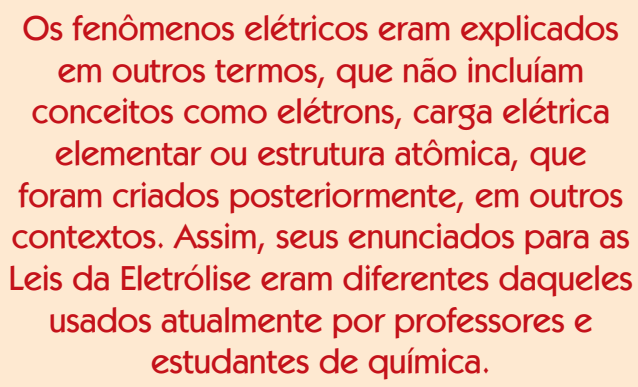

\section{Notas Stock, 1991)}

Científico e Tecnológico (CNPq) pelo financiamento (processos 426519/2016 e 307652/2017-3). paços faltantes, embora esses efeitos ainda não houvessem sido observados (Faraday, 1839, p. 102, nota de rodapé).

${ }^{2}$ A quinta seção corresponde a uma comunicação feita por Faraday à Royal Society originalmente em junho de 1833.

${ }^{3}$ Em termos atuais, "t" seria chamado de aterramento

${ }^{4} \mathrm{Em}$ linguagem atual, pode-se dizer que a mancha se deve à formação de íons triiodeto resultantes da interação do iodo elementar com o excesso de íons iodeto.

${ }^{5}$ No instrumento utilizado por Faraday, uma batida do relógio correspondia a 0,4 segundos.

${ }^{6}$ Usando linguagem atual, podemos exemplificar a primeira Lei da Eletrólise considerando a eletrólise ígnea do cloreto de sódio. Suponha que a quantidade de sódio depositada no cátodo durante uma hora, mantendo-se a corrente

Faraday realizou uma série de estudos fundamentais sobre os fenômenos elétricos, muitos dos quais relacionados à eletrólise. Neste artigo, destacamos alguns experimentos de Faraday que representam os primeiros passos rumo às Leis da Eletrólise. É importante observar que Faraday enfrentou diversas dificuldades, como a necessidade de um instrumento para medir a quantidade de eletricidade envolvida na eletrólise. Além disso, o panorama teórico de sua época era bem diferente do nosso. Havia dificuldades teóricas importantes: por exemplo, era difícil explicar por que a massa de substância formada ou decomposta na eletrólise dependia da quantidade de eletricidade, mas não da "intensidade" da pilha (isto é, da diferença de potencial). Os fenômenos elétricos eram explicados em outros termos, que não incluíam conceitos como elétrons, carga elétrica elementar ou estrutura atômica, que foram criados posteriormente, em outros contextos. Assim, seus enunciados para as Leis da Eletrólise eram diferentes daqueles usados atualmente por professores e estudantes de química. As explicações que usamos atualmente, envolvendo partículas de matéria, partículas de carga elétrica e conceitos da termodinâmica, viriam a se consolidar apenas no início do século XX (Guralnick, 1979).

\section{Agradecimentos}

PAP agradece ao Conselho Nacional de Desenvolvimento elétrica uniforme, seja de 30 gramas. Se fizermos o mesmo processo durante duas horas, com a mesma corrente elétrica sendo mantida, a quantidade de sódio depositada será de 60 gramas.

${ }^{7}$ Um grão equivale a $0,064 \mathrm{~g}$.

${ }^{8}$ Foi mantido aqui o número de algarismos significativos relatados por Faraday em seu texto.

${ }^{9}$ Neste artigo, utilizamos uma notação moderna para representar os cálculos por regra de três, apenas por ser mais familiar aos leitores atuais, mas não é a representação que se encontra na publicação original. Por exemplo, o cálculo do peso equivalente do estanho foi assim representado por Faraday: "0.49742 : $3 \cdot 2:: 9$ o equivalente da água está para $57 \cdot 9$, que deve portanto ser o equivalente do estanho".

\footnotetext{
Mateus Carneiro Guimarães dos Santos (mcarneirog@usp.br), licenciado em Química pela UFS, mestre em Educação para a Ciência pela UEM, doutorando em Ensino de Química pela USP e membro do Grupo de Pesquisa em História da Ciência e Ensino de Química (GHQ). São Paulo, SP - BR. Paulo Alves Porto (palporto@ iq.usp.br), bacharel e licenciado em Química pela USP, mestre e doutor em Comunicação e Semiótica pela PUC-SP, livre docente em Ensino de Química pela USP, é professor do Instituto de Química da USP e coordenador do Grupo de Pesquisa em História da Ciência e Ensino de Química (GHQ). São Paulo, SP BR. Neide Maria Michellan Kiouranis (nmmkiouranis@gmail.com), licenciada em Química, mestre em Ensino de Ciências - Modalidade Química pela USP, Doutora em Ensino de Ciências pela UNESP, é docente do Departamento de Química da Universidade Estadual de Maringá. Maringá, PR - BR.
} 


\section{Referências}

BALDINATO, J. O. A química segundo Michael Faraday: um caso de divulgação científica no século XIX. 2009. Dissertação (Mestrado em Ensino de Química) - Faculdade de Educação, Instituto de Física, Instituto de Química, Instituto de Biociências. Universidade de São Paulo, São Paulo.

BENCE-JONES, H. Life and Letters of Michael Faraday, vol. I, $2^{\text {nd }}$. ed. London: Longmans, Green and Co., 1870.

CAMEL, T. O.; KOEHLER, C. B. G. e FILGUEIRAS, C. A. L. A química orgânica na consolidação dos conceitos de átomo e molécula. Química Nova, v. 32, n. 2, p. 543-553, 2009.

DRENNAN, O. J. Faraday's contribution to electrolytic solution theory. Journal of Chemical Education, v. 42, n. 12, p. 679-681, 1965.

FARADAY, M. Experimental Researches in Electricity. London: Richard and John Edward Taylor, 1839.

GURALNICK, S. M. The Contexts of Faraday's Electrochemical Laws. Isis, v. 70, n. 1, p. 59-75, 1979.
IHDE, A. J. The Development of Modern Chemistry. New York: Dover, 1984.

JAMES, F. A. J. L. (Ed.). The correspondence of Michael Faraday: 1811-1831, vol. 1. Londres: IET, 1991.

MORUS, I. R. The Sociology of Sparks: An Episode in the History and Meaning of Electricity. Social Studies of Science, v. 18, n. 3, p 387-417, 1988.

ROSS, S. Faraday Consults the Scholars: The Origins of the Terms of Electrochemistry. Notes and Records of the Royal Society of London, v. 16, n. 2, p. 187-220, 1961.

RUSSEL, B. História do Pensamento Ocidental. Rio de Janeiro: Nova Fronteira, 2017.

STOCK, J. T. The pathway to the laws of electrolysis. Bulletin for the History of Chemistry, v. 11, p. 86-92, 1991.

THOMAS, J. M. Michael Faraday and the Royal Institution: The Genius of Man and Place. New York: Taylor and Francis, 1991.

THOMPSON, S. P. Michael Faraday: his life and work. New York: Forgottenbooks, 1898.

Abstract: Michael Faraday towards the Laws of Electrolysis: some experiments. This paper focuses on some of the experiments regarding phenomena related to electrolysis conducted by the English scientist Michael Faraday (1791-1867) and published in his series of books entitled Experimental Researches in Electricity. Faraday investigated the effects of the various types of electricity known in mid-19 $9^{\text {th }}$-century and assumed that all types of electricity were a single phenomenon which manifested itself in different forms. These experiments led him to elaborate what are known as the two Laws of Electrolysis.

Keywords: Faraday, electrolysis, history of science 